\title{
LA JUSTICIA ADMINISTRATIVA EN EL ESTADO DE MICHOACÁN. IMPLICACIONES Y RETOS
}

\author{
Administrative justice in the State of Michoacán. Implications and challenges
}

\author{
Daniel TOVAR REYES \\ Carlos Salvador RODRÍGUEZ CAMARENA²
}

\begin{abstract}
Sumario:
I. Los antecedentes del juicio contencioso administrativo en el Estado de Michoacán. II. Modelos de sentencias en el Juicio Contencioso Administrativo. III. Contexto actual de la justicia administrativa en el Estado de Michoacán. IV. Implicaciones y retos de la justicia administrativa en Michoacán. V. Fuentes de información.
\end{abstract}

Resumen. Existe la preocupación por parte de los aplicadores del derecho y doctrinarios en la materia de justicia administrativa, sobre cómo hacer efectivo el cumplimiento de las sentencias definitivas que condenan a una autoridad en el juicio contencioso administrativo. El caso del Estado de Michoacán no es la excepción, ya que no se puede lograr el cumplimiento de todas las sentencias emitidas por el Tribunal de Justicia Administrativa del Estado de Michoacán. Por tanto, se necesita realizar un análisis sobre en qué escenario se encuentra la administración de justicia en materia administrativa en Michoacán, y cuáles son sus implicaciones y retos que presenta actualmente.

Palabras claves: Justicia administrativa. Sentencia. Autoridad Administrativa. Cumplimiento.

Abstract. There is concern by the applicators of law and doctrine in the field of administrative justice, on how to enforce compliance with the final judgment condemning authority in the administrative contentious trial. In the case of Michoacán wich is not the exception, you cannot achieve compliance with all the judgments from the Court of Administrative Justice of the State of Michoacán. Therefore, it is necessary an analysis on what stage the administration of justice in administrative matters in Michoacán is and what are the implications and challenges currently present.

Key words: Administrative Law. Judgment. Administrative Authority. Compliance.

I. LOS ANTECEDENTES DEL JUICIO CONTENCIOSO ADMINISTRATIVO EN EL ESTADO DE MICHOACÁN

El Tribunal de Justicia Administrativa del Estado de Michoacán de Ocampo, es uno de los Tribunales de justicia en materia administrativa de creación más reciente en México. Se

\footnotetext{
${ }^{1}$ Maestro en Derecho. Universidad Michoacana de San Nicolás de Hidalgo.

${ }^{2}$ Doctor en Derecho. Universidad Michoacana de San Nicolás de Hidalgo.
} 
instauró y empezó a funcionar el 2 de enero de $2008 ;^{3}$ es decir, en esto momentos cuenta con ocho años de funcionamiento, y se puede decir que su instalación derivó de la creciente demanda de la ciudadanía de que se les administrara justicia en materia administrativa. En opinión del Magistrado Sergio Flores Navarro, las personas no sólo tienen la necesidad de un medio de defensa contra los actos de la administración pública de tribunales de simple anulación, sino de plena jurisdicción. ${ }^{4}$

Como antecedente, vale la pena mencionar cómo se resolvían antes los actos administrativos que eran violatorios de los derechos humanos de los particulares; resulta importante saber quiénes impartían justicia en esta materia en contra de actos de la administración de pública en Michoacán. Humberto Enrique Ruiz Torres apunta que cuando en México no había tribunales de lo contencioso administrativo, el juicio de Amparo servía como medio de defensa para combatir los actos de la administración pública, ${ }^{5}$ sometiendo estos actos al examen de su legalidad. Así, estos tipos de conflictos eran conocidos y resueltos por tribunales del Poder Judicial de la Federación. ${ }^{6}$

En ese contexto, Luis Rivera Montes de Oca afirma que después de varios años de un sistema de administración de justicia en materia administrativa y en reclamo de la ciudadanía, se crearon las condiciones sociales, políticas y económicas que hicieron posible la instalación en la mayoría de los Estados de la República, de tribunales de justicia contencioso administrativa; y señala los Estados que cuentan ya con tribunales en esta materia:

Al cabo de más de 70 años en que nuestro país cuenta con un sistema de impartición de justicia administrativa propio, 29 estados y el Distrito Federal cuentan con tribunales de lo contencioso administrativo; los estados de Chiapas y Puebla son los únicos que no cuentan con este tipo de tribunales.

En marzo de 1971 se publica la Ley que crea el Tribunal de lo Contencioso Administrativo del Distrito Federal, que es el primero de naturaleza local. La creación de este tribunal motivó el nacimiento de sus similares en los estados de Sinaloa (1976), Sonora (1977), Hidalgo (1981), Jalisco (1983), Querétaro (1985), Guanajuato (1987), Estado de México (1987), siendo lo más recientes

\footnotetext{
${ }^{3}$ Estado de Michoacán, Congreso Legislativo del Estado de Michoacán, “Código de Justicia Administrativa del Estado de Michoacán de Ocampo", Periódico Oficial del Estado de Michoacán, 27 de agosto de 2007, última reforma el día 14 de diciembre de 2012, p. 64, (en línea) docs.mexico.justia.com.s3.amazonaws.com/ estatales/michoacan/codigo-de-justicia-administrativa-del-estado-de-michoacan-de-ocampo.pdf, consultado el día 12 de enero de 2015.

${ }^{4}$ FLORES NAVARRO, Sergio, “Origen, Estructura y Organización de los Órganos de Justicia Administrativa en Michoacán”, en Fernández Ruiz, Jorge y Otero Salas, Filiberto (coord.), Justicia Contenciosa Administrativa Congreso Internacional, México, Ed. UNAM, 2013, p. 867.

5 Aun existen tres entidades federativas (Chihuahua, Coahuila y Puebla) que carecen de tribunales de lo contencioso administrativo. Aunque Puebla y Coahuila ya modificaron sus constituciones para permitir la creación de los tribunales (vid. Constitución Política del Estado Libre y Soberano de Puebla, artículos 12 fracción X y 57 fracción XXXI; para Coahuila, artículos 67 fracción XXX, 136 apartado B, de la Constitución Política del Estado de Coahuila de Zaragoza), no existen leyes reglamentarias ni se han instalado los tribunales. Par el caso de Chihuahua ni siquiera se ha modificado la constitución para efectos de que pueda ser considerada la creación de los tribunales de lo contencioso administrativo.

${ }^{6}$ RUIZ TORRES, Humberto Enrique, Curso General de Amparo, México, Ed. Oxford, 2007, pp. 10-11.
} 
los de Zacatecas (2000), Nayarit (2002), Quintana Roo (2000), Durango (2004), Oaxaca (2006) y Michoacán (2007). ${ }^{7}$

El Tribunal de Justicia Administrativa en el Estado de Michoacán tiene como fundamento jurídico para su institución, el artículo 95 la Constitución Política del Estado de Michoacán de Ocampo. La Constitución lo define como un

[...] órgano autónomo, independiente en sus resoluciones y de jurisdicción plena en materia administrativa con sujeción a los principios de igualdad, publicidad, audiencia y legalidad; y establece su competencia para dirimir, resolviendo en forma definitiva, las controversias que se susciten por actos $u$ omisiones de naturaleza administrativa ofiscal entre el Poder Ejecutivo, los ayuntamientos, los organismos autónomos, las entidades u organismos descentralizados o desconcentrados, estatales o municipales y los particulares. La ley determinará las atribuciones y procedimientos al tenor de la presente Constitución. ${ }^{8}$

La creación del Tribunal se llevó a cabo mediante la ejecución del decreto de fecha 21 de diciembre de 2006. Por otro lado, el día $1^{\circ}$ de agosto de 2007 se aprobó el Código de Justicia Administrativa del Estado de Michoacán de Ocampo, el cual se publicó en el Periódico Oficial del Estado el día 23 de agosto de 2007. El tribunal se comenzó sus trabajos en el año 2008. ${ }^{9}$

Este órgano jurisdiccional, desde la fecha en que se instauró, ha tenido una gran demanda por parte de la ciudadanía. Desde la fecha en que empezó funciones al día 30 de septiembre de 2013, se emitieron 2186 sentencias definitivas: en el 2008, 78 sentencias; en 2009, 191; en 2010 se emitieron 320; para el año 2011, fueron 405; 565 sentencias para el 2012; y 627 para el año $2013,{ }^{10}$ Lo anterior denota que cada vez va más en aumento el conocimiento de controversias en ésta materia por parte del tribunal.

\section{MODELOS DE SENTENCIAS EN EL JUICIO CONTENCIOSO ADMINISTRATIVO}

Para comprender la justicia administrativa en el Estado de Michoacán resulta necesario hablar sobre el tipo de sentencias que emite el tribunal encargado de realizar ésta actividad en el Estado. Emilio Margáin Manautou apunta las diferencias que existen entre las sentencias

\footnotetext{
7 RIVERA MONTES DE OCA, Luis, "La estructura y Organización de los Órganos de Justicia Contenciosa Administrativa”, en Fernández Ruiz, Jorge y Otero Salas, Filiberto (coord.), Justicia Contenciosa Administrativa Congreso Internacional, México, Ed. UNAM, 2013, pp. 640-641.

8 Estado de Michoacán, Congreso Legislativo del Estado de Michoacán, "Constitución Política del Estado Libre y Soberano de Michoacán de Ocampo", Periódico Oficial del Estado de Michoacán, 7, domingo 10, jueves 14, domingo 17, jueves 21, domingo 24, jueves 28, de febrero; domingo 3, jueves 7 , domingo 10 y jueves 14 de marzo de 1918, última reforma el día 25 de junio de 2014, (en línea), http://transparencia.congresomich.gob. $\mathrm{mx} / \mathrm{media} /$ documentos/trabajo_legislativo/CONSTITUCION_POLITICA_DEL_ESTADO_REF.22_DE_ JUNIO_DE_2014.pdf, consultado el día 13 de enero de 2015.

9 Tribunal de Justicia Administrativa de Michoacán de Ocampo, Antecedentes Históricos del Tribunal de Justicia Administrativa del Estado de Michoacán de Ocampo, (en línea), http://transparencia.congresomich.gob. $\mathrm{mx} / \mathrm{media} /$ documentos/trabajo_legislativo/CÓDIGO_DE_JUSTICIA_ADMINISTRATIVA_DEL_ESTADO_DE_MICHOACÁN_DE.pdf.

${ }^{10}$ Oficio TJAM/SA/285/2013, con fecha 30 de octubre de 2013, mediante el cual el Tribunal da respuesta a la solicitud de información, el cual se encuentra suscrito por el licenciado Héctor Gómez Trujillo, Secretario Administrativo y Responsable de Acceso a la Información Pública del Tribunal de Justicia Administrativa del Estado de Michoacán de Ocampo.
} 
declarativas y las sentencias de condena. Menciona que la primera es aquella donde el actor en el juicio contencioso administrativo busca una declaración como existente, es decir, una sentencia declarativa busca confirmar un derecho a la pretensión; la de condena, por su parte, además de obtener como efecto la determinación de un derecho, también constituye un título para la realización forzosa de la relación declarativa. Agrega que las sentencias que se emitan en un juicio contencioso administrativo, ya sean de nulidad o de condena, deben cumplirse. ${ }^{11}$ Asimismo, Humberto Delgadillo señala que la sentencia en el juico contencioso Administrativo puede ser de anulación: el juzgador se limita sólo a declarar la validez o nulidad del acto, y de plena jurisdicción, cuando se emite la sentencia de condena; es decir, sólo menciona que hay sentencias declarativas y de condena en esta clase de juicios. ${ }^{12}$

Aplicando ésta clasificación de sentencias al Juicio Contencioso Administrativo en el Estado Michoacán, el tribunal emite sentencias declarativas y de condena, de conformidad con lo establecido en los artículos 278 y 280 del Código de Justicia Administrativa del Estado de Michoacán de Ocampo, que literalmente establecen lo siguiente:

Artículo 278. Los efectos de la sentencia serán:

I. Resolver sobre la legalidad y validez de la resolución o del acto impugnado;

II. Decretar, total o parcialmente, la nulidad del acto o de la resolución combatida y las consecuencias que de éstos se deriven; debiendo precisar con claridad la forma y términos en que la autoridad deba cumplir;

III. Modificar el acto o resolución impugnada; o,

IV. En su caso, imponer la condena que corresponda.

$[\ldots]$

Artículo 280. Las sentencias que declaren fundada la pretensión del actor, dejarán sin efecto el acto reclamado y fijarán el sentido de la resolución que deba dictar la autoridad responsable, para restablecer al actor en el ejercicio de sus derechos.

Cuando además de la pretensión de nulidad, se ejerza la de condena por daños y perjuicios, determinada su procedencia por sentencia ejecutoriada, el pago deberá efectuarse a más tardar dentro de los tres primeros meses del siguiente ejercicio presupuestal, con la actualización y los recargos establecidos por la legislación fiscal del Estado, desde la emisión de la sentencia. ${ }^{13}$

En el momento procesal oportuno, el aplicador del derecho resolverá si un acto es nulo o no, y si procede en la misma sentencia condenar a la autoridad a un pago monetario en favor del particular.

\footnotetext{
${ }^{11}$ MARGÁIN MANAUTOU, Emilio, De lo Contencioso Administrativo de Anulación o de Ilegitimidad, Ed. Décimo quinta, México, Ed. Porrúa, 2013, pp. 411, 412, 425.

${ }^{12}$ DelGadillo GUTIÉRREZ, Luis Humberto, Principios de Derecho Tributario, Quinta Ed., México, Ed. Limusa, 2012, p. 201.

${ }^{13}$ Estado de Michoacán, Congreso Legislativo del Estado de Michoacán, "Código de Justicia Administrativa del Estado de Michoacán de Ocampo", Periódico Oficial del Estado de Michoacán, 27 de agosto de 2007, última reforma el día 14 de diciembre de 2012, pp. 57, 59, (en línea) docs.mexico.justia.com.s3.amazonaws.com/ 


\section{CONTEXTO ACTUAL DE LA JUSTICIA ADMINISTRATIVA EN EL ESTADO DE MICHOACÁN}

Para referirnos a la administración de justicia administrativa en Michoacán, es necesario apuntar las diferentes cuestiones que surgen al buscar el cumplimiento de las sentencias que condenan a la autoridad administrativa a pagar una cantidad monetaria; es decir, cuando en la sentencia definitiva que pone fin al juico contencioso administrativo se declara la nulidad del acto impugnado, la misma sentencia condena al pago de daños y perjuicios que se le ocasionaron al particular con motivo de la emisión de un acto de autoridad que en la sentencia fue declarado nulo. Resulta común que la autoridad administrativa no cumpla de manera voluntaria con la sentencia. Al tratar de realizar su cumplimiento de forma forzosa a través del procedimiento de ejecución previsto en el Código de Justica Administrativa del Estado de Michoacán, resulta difícil de lograr el fin perseguido con un procedimiento lento. ${ }^{14}$

Con el objeto de corroborar el nivel de cumplimiento de sentencias, se solicitó información al Tribunal de Justicia Administrativa del Estado de Michoacán, sobre los siguientes tópicos:

1. ¿Cuántas sentencias definitivas se han emitido desde que se instauró el Tribunal de Justicia Administrativa del Estado de Michoacán de Ocampo a 2013?

2. ¿Cuántas de esas sentencias definitivas emitidas en el periodo anterior mencionado se han cumplido? ¿Cuántas de forma voluntaria y cuántas de forma forzosa, es decir, a través del procedimiento de ejecución de sentencia previsto en el código de la materia?

3. ¿Cuántas sentencias definitivas del periodo aludido en el punto número uno, son de condena a la autoridad demandada a pago de indemnización por concepto de daños y perjuicios al particular?

4. ¿Cuántas sentencias definitivas de condena a la autoridad demandada se han cumplido de manera forzosa y cuántas en forma voluntaria? ${ }^{15}$

El Tribunal de Justicia Administrativa del Estado de Michoacán contestó mediante oficio TJAM/SA/285/2013, con fecha 30 de octubre de 2013, lo siguiente:

$[\ldots]$

Le informo que desde la fecha de creación y al 30 de septiembre de 2013 se han emitido un total de 2186 (dos mil ciento ochenta y seis) sentencias definitivas en el Tribunal de Justicia del Estado de Michoacán de Ocampo

$[\ldots]$

estatales/michoacan/codigo-de-justicia-administrativa-del-estado-de-michoacan-de-ocampo.pdf, consultado el día 29 de septiembre de 2014.

${ }^{14}$ Hemos dado seguimiento a dos juicios de nulidad (JA-595/2013-I y JA-594/2013-III) que fueron tramitados ante el Tribunal de Justica Administrativa del Estado de Michoacán de Ocampo. En ambos se ha tramitado la ejecución forzosa de la sentencia para conseguir el pago por parte de la autoridad la condenada. A pesar de lo anterior, la fecha, las autoridaes se han negado a cumplir con la sentencia.

${ }^{15}$ Escrito de Solicitud de información al Presidente de Tribunal de Justicia Administrativa del Estado de Michoacán de Ocampo, del día 02 de octubre de 2013, suscrito por el licenciado en Derecho Daniel Tovar Reyes. 
Le informo que respecto a este punto, la (sic) áreas jurisdiccionales me manifestaron que no cuentan con los registros estadísticos en los términos que se solicitan, lo anterior con fundamento en el tercer párrafo in fine, del artículo 9 de la Ley de Transparencia y Acceso a la Información Pública del Estado de Michoacán de Ocampo.

\section{$[\ldots]$}

Le informo que respecto a esta petición, en 88 (ochenta y ocho) sentencias que se han condenado a la autoridad responsable al pago de daños y perjuicios al particular.

\section{$[\ldots]$}

Le informo que respecto a esta petición, en 50 (cincuenta) sentencias donde se ha condenado a la autoridad al pago de daños y perjuicios al particular se ha instaurado el procedimiento de ejecución. ${ }^{16}$

\section{$[\ldots]$}

En razón de lo anterior, desde la fecha en que se instauró el Tribunal de Justicia Administrativa, es decir, desde el año 2008 al día 30 de septiembre de 2013, se habían emitido 88 sentencias en las que se condenó a la autoridad a pagar indemnización por daños y perjuicios al particular, de las cuales en 50 se había instaurado el procedimiento de ejecución. En mucho más de la mitad de sentencias la autoridad responsable no había cumplido con lo determinado en ellas, mostrando un comportamiento absurdo, pues es incongruente que las autoridades que forman parte de la administración pública y que llevan a cabo la ejecución de las normas jurídicas en el Estado, no cumplan con una norma individualizada que es una sentencia adversa a ellas. Surge, así, una interrogante: ¿dónde queda el Estado de Derecho? En nuestra opinión, una autoridad no debe tener un comportamiento de rebeldía como pueden tenerlo algunos particulares en procedimientos jurisdiccionales. La información proporcionada por el Tribunal Justica Administrativa del Estado de Michoacán ratifica un dato importante: en la mayoría de los casos la autoridad responsable no cumple de manera voluntaria la sentencia que los condena a pagar una indemnización por daños y perjuicios.

Rubén Herrera Rodríguez, en un trabajo sobre el cumplimiento de las sentencias condenatorias en el contencioso administrativo en Michoacán, realizó una entrevista a cada uno de los aplicadores del derecho en la materia contenciosa administrativa en 18 de los 29 órganos jurisdiccionales que existen en el país. ${ }^{17}$ Los juzgadores que entrevistó pertenecen a los órganos jurisdiccionales de las Estados Baja California, Baja California Sur, Estado de México, Guanajuato, Guerrero, Hidalgo, Michoacán, Morelos, Nayarit, Oaxaca, Querétaro, San Luis Potosí, Sinaloa, Tabasco, Tlaxcala, Yu-

\footnotetext{
${ }^{16}$ Oficio TJAM/SA/285/2013, con fecha 30 de octubre de 2013, mediante el cual el Tribunal da respuesta a la solicitud de información, el cual se encuentra suscrito por el licenciado Héctor Gómez Trujillo, Secretario Administrativo y Responsable de Acceso a la Información Pública del Tribunal de Justicia Administrativa del Estado de Michoacán de Ocampo. Las palabras en negritas están en el original.

${ }^{17}$ HERRERA RODRÍGUEZ, Rubén, "El cumplimiento de las Sentencias Condenatorias en el Proceso Administrativo en el Estado de Michoacán y los Medios de Apremio para su Ejecución" (Tesis para obtener el grado de doctor en Derecho), Morelia, Michoacán, Instituto Internacional del Derecho y del Estado, 2013, p. 176 .
} 
catán, Zacatecas y Distrito Federal. ${ }^{18}$ Estos aplicadores del derecho estuvieron sujetos a diversas preguntas cerradas, entre las que se encontraban las siguientes:

$[\ldots]$

2. ¿El marco normativo del órgano jurisdiccional donde Usted se desempeña, es suficiente para lograr el cabal cumplimiento de las sentencias dictadas en contra de la autoridad?

$[\ldots]$

6. ¿Considera que el embargo de bienes públicos, serviría para superar la renuencia de las autoridades a cumplir las sentencias de condena?

$[\ldots]$

10. ¿Estima Usted que una reiterada falta de cumplimiento de las sentencias favorables al particular, conlleve a la falta de credibilidad del órgano que la emite? ${ }^{19}$

Las respuestas que obtuvo el autor citado fueron las siguientes:

b) Respecto de la pregunta número 2, la mayoría en un 51.8\% (16 quince entrevistados) manifestó que el marco normativo del órgano jurisdiccional donde se desempeña no es suficiente para lograr el cabal cumplimiento de las sentencias dictadas en contra de la autoridad, un 44.4 (12 entrevistados) señaló que si, y 37\% (un entrevistado) mencionó que es regular.

$[\ldots]$

f) Con relación a la pregunta 6, de que si el embargo de bienes públicos, serviría para superar la renuencia de las autoridades a cumplir sentencias de condena, un 51.8\% (14) de los entrevistados considera que sí, un $37 \%$ (10) estima que no y un $7.4 \%$ (2) señalo que pudiese contribuir, un $3.7 \%$ (1) no respondió.

$[\ldots]$

j) Con relación a la pregunta 10, de que si se estima que una reiterada falta de cumplimiento de las sentencias favorables al particular, conllevaría a la falta de credibilidad del órgano que la emite, un $96.2 \%$ (26 entrevistados) respondió que sí, y solo el 3.7\% (1) dijo que tal vez. ${ }^{20}$

Con base en los datos apuntados, se colige en primer lugar, que la mayoría de los juzgadores -entre ellos los del tribunal de Justicia Administrativa del Estado de Michoacán- en un $51.8 \%$ manifestó que el marco normativo con el que se cuenta en los tribunales para llevar a cabo el cumplimiento de una sentencia condenatoria a autoridad administrativa, era insuficiente, o dicho en otras palabras, no resulta eficaz el mecanismo de ejecución de sentencia. En segundo lugar, se deduce que la mayoría de los entrevistados (51.8\%) considera al embargo de bienes públicos como el medio más eficaz. El autor no aclara si los juzgadores ya tienen

\footnotetext{
${ }^{18}$ Ídem.

${ }^{19}$ Ibídem, pp. 177-178.

${ }^{20}$ Ibídem, pp. 180, 184, 187.
} 
este medio a su disposición. El embargo serviría para superar la renuencia de las autoridades a cumplir lo determinado en la resolución definitiva; es decir, que más de la mitad de los juzgadores a los que se les aplicó la entrevista consideran el embargo como la solución para vencer la rebeldía de las autoridades a cumplir. Finalmente, la mayoría de los titulares de órganos jurisdiccionales (96.2\%), mencionó que el hecho de no cumplir con las sentencias en materia contenciosa administrativa que condena a la autoridad administrativa, traería como consecuencia que no se tenga confianza en estos tribunales como impartidores de justicia, ya que un tribunal que no puede ejecutar sus sentencias no justifica su existencia.

También robustece la afirmación anterior, el informe de actividades correspondiente al año 2014. En ese documento, Sergio Flores Navarro, magistrado presidente del Tribunal de Justicia Administrativa del Estado de Michoacán, en el apartado III.3 Cumplimiento de las sentencias dictadas por el Tribunal de Justicia Administrativa de Michoacán de Ocampo, hace alusión a que el Tribunal de Justicia Administrativa del Estado de Michoacán tiene como finalidad, hacer posible el derecho fundamental contenido en el artículo 17 de la Constitución Política de los Estados Unidos Mexicanos relativo a la tutela judicial efectiva, agregando que dicho derecho impone la obligación a los juzgadores de asegurar que sus fallos judiciales se cumplan, logrando con ello la restitución plena del ciudadano en sus derechos violentados. ${ }^{21}$

No obstante, en el mismo informe el magistrado Sergio Flores Navarro implícitamente reconcoe que existen casos en lo que no se cumple cabalmente con los fallos emitidos por el Tribunal de Justicia Administrativa del Estado, debido a la carencia de los instrumentos jurídicos adecuados:

Ha quedado de manifiesto en el quehacer jurisdiccional diario, que el procedimiento para la ejecución de las sentencias establecido en el Código de Justicia Administrativa del Estado, merece una revisión legislativa para eficientar los mecanismos y procedimientos para asegurar el cumplimiento efectivo de la sentencia con la celeridad necesaria. ${ }^{22}$

En esa perspectiva, se observa claramente el reconocimiento por parte del Magistrado en el sentido de que el procedimiento de ejecución requiere una revisión legislativa para hacer efectivos los mecanismos que buscan el cumplimiento de la sentencia. De tal guisa, se tiene que el procedimiento de ejecución de sentencia en el juicio contencioso administrativo en el Estado de Michoacán no cumple con la finalidad que se estableció; es decir, no lleva al cumplimiento cabal de las sentencias que sean adversas a la autoridad.

En el rubro de cumplimiento de sentencias, el informe en comento refiere que en 2014, hay cinco juicios de nulidad en los que no se ha cumplido con las sentencias que condenan a las autoridades a pagar una cantidad monetaria, derivado su rebeldía a dar cumplimiento a la misma, a pesar de que tanto las Ponencias Instructoras como la Sala Colegiada del Tribunal han empleado todos los diversos medios de apremio establecidos por el capítulo décimo

\footnotetext{
${ }^{21}$ FLORES NAVARRO, Sergio, Informe Anual de Actividades del Tribunal de Justicia Administrativa del Estado de Michoacán, presentando ante el H. Congreso de Michoacán de Ocampo, p. 5, (en línea) http://transparencia.congresomich.gob.mx/media/documentos/gacetas/GACETA_142_C_19-02-2015.pdf, consultado el día 05 de junio de 2015.

${ }^{22}$ Ídem.

CienCIA JuRÍDicA. Departamento de Derecho. División de Derecho, Política y Gobierno, Universidad de Guanajuato - Año 5, No. 10, 2016
} 
segundo del Libro Quinto del Código de Justicia Administrativa del Estado, sin obtener resultado favorable. ${ }^{23}$

Así, en el informe faltó referirse al expediente JA-594/2013-III, tramitado y llevado por la Tercera Ponencia del Tribunal de Justicia Administrativa, dejando en duda si lo que refiere el informe son datos totales o sólo versan sobre la Primera Ponencia del Tribunal en mención, pues el número romano al final de cada número de expediente refiere la ponencia que está conociendo del juicio de nulidad correspondiente. Esto genera la presunción de que hay más juicios de nulidad que están sin cumplirse, en adición a los que se citan en el informe. Por ello, es de cuestionarse si el Tribunal de Justicia Administrativa del Estado de Michoacán tiene la posibilidad real de hacer uso de su facultad de plena jurisdicción en todos los casos que atiende, que realmente cuenta con las facultades para administrar justicia en los términos del artículo 17 de la Constitución Política del Estados Unidos Mexicanos, o si sólo realiza tramites que quedan en sentencias que son meras declaraciones de derecho.

Por tanto, a partir de los datos que se pudieron analizar sobre éste tema, se puede obtener un perfil de la realidad en la que se encuentra la justicia administrativa del Estado de Michoacán: existe una justicia administrativa impartida por un órgano constitucional autónomo, independiente en sus resoluciones y con jurisdicción plena, pero la justicia que tiene la posibilidad de impartir es incompleta, porque no existen mecanismos legales (solo medios de apremio establecidos en el código de la materia carecen del imperio necesario) que fuercen a autoridades a cumplir con lo que determinan las sentencias que emite éste órgano jurisdiccional.

\section{IMPLICACIONES Y RETOS DE LA JUSTICIA ADMINISTRATIVA EN MICHOACÁN}

De lo hasta ahora analizado en el presente ensayo, se pueden colegir algunas implicaciones que derivan de la forma de administrar la justicia administrativa en el Estado de Michoacán.

1. La primera consecuencia que resalta con esta forma de impartir justicia en la materia en comento, es que no se da cumplimiento a un derecho fundamental de las personas: la tutela judicial efectiva. En una sentencia administrativa lo que se busca el sometimiento de la autoridad administrativa al derecho y al respeto de los derechos humanos de todos los administrados que reconoce la Constitución Política de los Estados Unidos Mexicanos.

En esa lógica, hablar de justicia administrativa o de cualquier otra materia relacionada con la impartición de justicia, es traer a colación el artículo $1^{\circ}$ en relación con el 17 de la Constitución Política de los Estados Unidos Mexicanos. Entre ambos preceptos se establecen la tutela judicial y el debido proceso, derechos ambos que marcan la pauta para obtener justicia plena. Al acudir ante un tribunal, el justiciable tiene la expectativa de obtener de los tribunales resoluciones justas de manera pronta, completa e imparcial.

En concordancia, todas las leyes federales y locales que reglamenten esos derechos, deben establecer los medios necesarios para que se garantice la independencia de los tribunales y la plena ejecución de sus resoluciones, con la finalidad de hacer efectivos los derechos humanos mencionados; sin embargo, en el Tribunal de Justicia Administrativa del Estado de

\footnotetext{
${ }^{23}$ Ibídem, p. 6. Los expedientes que refieren en el informe son JA-10o/2012-I, Alberto... -vs- Presidente Municipal de Pajacuarán, Michoacán, JA-427/2012-I, JA-109/2013-I y JA-0595/2013-I en contra del Ayuntamiento de Zitácuaro, Michoacán.
} 
Michoacán no acontece en todos los casos. Se ha discutido que existen diversas sentencias a las que las autoridades administrativas condenadas no han dado cumplimiento.

2. Derivado del incumplimiento de las sentencias y de la incapacidad del órgano jurisdiccional de obtener el cumplimiento cabal de las mismas, no sólo se violentan los artículos $1^{\circ} \mathrm{y}$ 17 de la Constitución, sino también los tratados internacionales-que constituyen el bloque de constitucionalidad en nuestro país - ${ }^{24}$ de los cuales el Estado mexicano forma parte y que tiene la obligación de acatar, de acuerdo a lo establecido por el artículo $1^{\circ}$ de la Constitución Política de los Estados Unidos Mexicanos:

Artículo 1o. En los Estados Unidos Mexicanos todas las personas gozarán de los derechos humanos reconocidos en esta Constitución y en los tratados internacionales de los que el Estado Mexicano sea parte, así como de las garantías para su protección, cuyo ejercicio no podrá restringirse ni suspenderse, salvo en los casos y bajo las condiciones que esta Constitución establece. ${ }^{25}$

$[\ldots]$

Ahora bien, refiriéndonos en especial a la tutela judicial en instrumentos internacionales, se transcriben algunos preceptos legales de la Convención Americana sobre Derechos Humanos —Pacto de San José- que de manera literal establecen:

Artículo 8. Garantías Judiciales

1. Toda persona tiene derecho a ser oída, con las debidas garantías y dentro de un plazo razonable, por un juez o tribunal competente, independiente e imparcial, establecido con anterioridad por la ley, en la sustanciación de cualquier acusación penal formulada contra ella, o para la determinación de sus derechos y obligaciones de orden civil, laboral, fiscal o de cualquier otro carácter.

\section{$[\ldots]$}

Artículo 25. Protección Judicial

1. Toda persona tiene derecho a un recurso sencillo y rápido o a cualquier otro recurso efectivo ante los jueces o tribunales competentes, que la ampare contra actos que violen sus derechos fundamentales reconocidos por la Constitución, la ley o la presente Convención, aun cuando tal violación sea cometida por personas que actúen en ejercicio de sus funciones oficiales.

\section{Los Estados Partes se comprometen:}

\footnotetext{
${ }^{24}$ Fix-Zamudio Héctor y Valencia Carmona Salvador, Las Reformas en Derechos Humanos, Procesos Colectivos, y Amparo Como Nuevo Paradigma Constitucional, México, Ed. Porrúa, 2013, pp. 11-12. Aquí los autores nos hablan de la teoría del bloque de constitucionalidad, la cual sirve para explicar que la constitucionalidad comprende no sólo el texto fundamental en vigor, sino también otros elementos, como es el caso mexicano de conformidad con el artículo $1^{\circ}$ Constitucional, en donde no sólo se abarca el texto escrito en la Constitución Política de los Estado Unidos Mexicanos, sino también una serie de instrumentos internacionales de derecho humanos, siempre cuando se hayan debidamente suscrito.

${ }^{25}$ México, H. Congreso de la Unión Cámara de Diputados, “Constitución política de los Estados Unidos Mexicanos", Diario Oficial de la Federación 5 de febrero de 1917, última reforma 27 de mayo de 2015, p. 1, (en línea) http://www.diputados.gob.mx/LeyesBiblio/pdf/1_o7jul14.pdf, consultado el día 12 de noviembre de 2014. 
a) a garantizar que la autoridad competente prevista por el sistema legal del Estado decidirá sobre los derechos de toda persona que interponga tal recurso;

b) a desarrollar las posibilidades de recurso judicial, y

c) a garantizar el cumplimiento, por las autoridades competentes, de toda decisión en que se haya estimado procedente el recurso. ${ }^{26}$

Los preceptos legales transcritos dejan en claro que las garantías judiciales se refieren a los principios de seguridad jurídica, legalidad y que en toda decisión de un tribunal debe garantizarse el cumplimiento de las decisiones judiciales de manera efectiva.

Aunado a lo anterior, el Pacto Internacional de Derechos Civiles y Políticos establece también cuestiones respecto a tutela judicial, los cuales mencionan lo siguiente:

\section{PARTE II}

\section{ARTÍCULO 2}

1. Cada uno de los Estados Partes en el presente Pacto se compromete a respetar y a garantizar a todos los individuos que se encuentren en su territorio y estén sujetos a su jurisdicción los derechos reconocidos en el presente Pacto, sin distinción alguna de raza, color, sexo, idioma, religión, opinión política o de otra índole origen nacional o social, posición económica, nacimiento o cualquier otra condición social.

2. Cada Estado Parte se compromete a adoptar con arreglo a sus procedimientos constitucionales y a las disposiciones del presente Pacto, las medidas oportunas para dictar las disposiciones legislativas o de otro carácter que fueren necesarias para hacer efectivos los derechos reconocidos en el presente Pacto y que no estuviesen ya garantizados por disposiciones legislativas o de otro carácter.

3. Cada uno de los Estados Partes en el presente Pacto se compromete a garantizar que:

a) Toda persona cuyos derechos o libertades reconocidos en el presente Pacto hayan sido violados podrán interponer un recurso efectivo, aun cuando tal violación hubiera sido cometida por personas que actuaban en ejercicio de sus funciones oficiales;

b) La autoridad competente, judicial, administrativa o legislativa, o cualquiera otra autoridad competente prevista por el sistema legal del Estado, decidirá sobre los derechos de toda persona que interponga tal recurso y a desarrollar las posibilidades de recurso judicial;

\footnotetext{
${ }^{26}$ Tratados e Instrumentos Internacionales Básicos en Derechos Humanos, Convención Americana Sobre Derechos Humanos (Pacto de San José), INmediación Asesores Publicitarios, Morelia, Michoacán, 2013, p. 214, 226. 
c) Las autoridades competentes cumplirán toda decisión en que se hayan estimado procedente el recurso. ${ }^{27}$

En este tenor, las autoridades competentes están obligadas a cumplir cualquier decisión de una autoridad judicial, administrativa o legislativa, o cualquiera otra competente. Esta cuestión denota que la tutela judicial debe estar en armonía con el artículo 17 de la Constitución Política de los Estados Unidos Mexicanos, que impone la obligación a los legisladores de que en las leyes federales y locales se establezca la plena ejecución de las resoluciones emitidas por los tribunales. Esta cuestión normativa no se cumple, lo que se traduce en violación a los derechos humanos de forma flagrante.

3. La reforma a la Constitución Política de los Estados Unidos Mexicanos del 10 de junio de 2011, introdujo nuevas instituciones jurídicas, entre ellas la de interpretación conforme. Tratándose de derechos humanos, las autoridades están obligadas a interpretar las normas que contengan derechos humanos de conformidad con la Constitución y con los tratados internacionales de la materia, otorgando en todo tiempo a las personas la protección más amplia. Además, la reforma estableció la obligación de todas las autoridades de promover, respetar, proteger y garantizar los derechos humanos de conformidad con los principios de universalidad, interdependencia, indivisibilidad y progresividad. En consecuencia, el Estado deberá prevenir, investigar, sancionar y reparar las violaciones a los derechos humanos, en los términos que establezca la ley.

Las cuestiones anteriores, establecidas en el artículo $1^{\circ}$ Constitucional ${ }^{28}$ obligan a todas las autoridades. El sistema judicial en México, de manera específica, está obligado a garantizar que todas las autoridades cumplan con la parte que les corresponde. El precepto constitucional también impide que cualquier autoridad administrativa esté por encima de los derechos humanos o que existan obstáculos que no permitan el cumplimiento de una sentencia en contra de las autoridades administrativas. Resulta absurdo que el discurso del Estado mexicano en la constitución sea, por un lado, el de garantizar y respetar los derechos humanos, y por otro, que las autoridades administrativas no cumplan con una sentencia que determine que su actuar fue no solo ilegal, sino que al mismo tiempo trajo una daño y perjuicio al particular.

4. Finalmente, como consecuencia de la ineficacia del cumplimiento de las sentencias, se puede señalar que se debe poner en tela de juicio la propia existencia de este tipo de tribunales y el presupuesto que se destina para su funcionamiento. Este presupuesto que se destina al órgano jurisdiccional puede tener otros fines más benéficos para la sociedad del Estado de Michoacán. Parafraseando a los clásicos, ${ }^{29}$ un tribunal que no puede ejecutar lo que decide, al final de cuentas es un tribunal que no existe. En este caso, sus funciones pueden perfectamente ser suplidas por un tribunal de Amparo, como se realizaba antes de que se instaurara el Tribunal de Justicia Administrativa del Estado. Aunque es cierto no se han aportado datos sobre el incumplimiento de las sentencias de amparo, también es cierto que el juez de amparo cuenta con la posibilidad de sancionar a la autoridad responsable separándola de su

\footnotetext{
${ }^{27}$ Tratados e Instrumentos Internacionales Básicos en Derechos Humanos, Pacto Internacional de Derechos Civiles y Políticos, INmediación Asesores Publicitarios, Morelia, Michoacán, 2013, p. 30, 31.

${ }^{28}$ FIX-ZAMUDIO Héctor y VALENCIA CARMONA Salvador, Op. Cit., nota 24, pp. 7, 24.

${ }^{29}$ Un derecho que carece de garantías no es un derecho. 
cargo y consignándolo ante el Juez de Distrito, mecanismo del que también carece el juez administrativo.

Por otro lado, para mejorar la eficacia en el cumplimiento de las sentencias del tribunal de lo contencioso administrativo, como retos se pueden destacar los siguientes:

a. En primer lugar, se sugiere una reforma para buscar un mecanismo de ejecución de sentencias en materia administrativa en el Estado de Michoacán que sea eficaz, sin necesidad de retardar de forma indefinida. Tal y como lo apuntó el magistrado Sergio Flores Navarro, las atribuciones que tiene actualmente el Tribunal de Justicia Administrativa michoacano merecen una revisión legislativa, de manera que los mecanismos y procedimientos sean eficientes para asegurar el cumplimiento efectivo de las sentencias. Actualmente se percibe, en los propios aplicadores del derecho en tribunal del Estado, decepción sobre los mecanismo con que actualmente cuentan para hacer cumplir una sentencia.

b. En ese orden de ideas, al establecerse un mecanismo de ejecución eficaz, el legislador debe allegarse de elementos que provengan de los problemas factuales que trata de resolver. El Derecho no puede darse bajo principios que no tengan ese contacto con el entorno social. En Michoacán tenemos un derecho contencioso administrativo establecido sobre bases que no corresponden a la realidad operacional. Cuando una sentencia determina que un acto administrativo es ilegal, y en consecuencia nulo, y además condena al pago de daños a favor del gobernado, y aun así otorga a la autoridad el privilegio de cumplir la sentencia cuando quiera hacerlo, pone de lado el derecho humano de los ciudadanos a que se les administre justicia de manera completa. A nada práctico conduce el hecho de que, a pesar de ganar un juicio contencioso administrativo, el particular quede en una situación de que no se ejecute la sentencia de un Juez o Magistrado. Deben entonces, dejarse de lado los dogmas que no están apegados a una realidad social y jurídica al momento de legislar.

c. Finalmente, un reto más para la justicia administrativa en Michoacán, es que los magistrados que se nombren hagan valer la plena jurisdicción de que están investidos, sometiendo a las autoridades administrativas al derecho, de manera que los gobernados se sientan realmente protegidos contra los actos de la administración pública que no cumplan con los requisitos establecidos en la ley.

\section{FUENTES}

BIBLIOGRÁFICAS

DELGADILlO GUTIÉRREZ, Luis Humberto, Principios de Derecho Tributario, Quinta Ed., México, Ed. Limusa, 2012.

FIX-ZAMUDIO Héctor y VALENCIA CARMONA Salvador, Las Reformas en Derechos Humanos, Procesos Colectivos, y Amparo Como Nuevo Paradigma Constitucional, México, Ed. Porrúa, 2013.

FLORES NAVARRO, Sergio, “Origen, Estructura y Organización de los Órganos de Justicia Administrativa en Michoacán”, en Fernández Ruiz, Jorge y Otero Salas, Filiberto (coord.), Justicia Contenciosa Administrativa Congreso Internacional, México, Ed. UNAM, 2013. 
MARGÁIN MANAUTOU, Emilio, De lo Contencioso Administrativo de Anulación o de Ilegitimidad, Ed. Décimo quinta, México, Ed. Porrúa, 2013.

RUIZ TORRES, Humberto Enrique, Curso General de Amparo, México, Ed. Oxford, 2007.

RIVERA MONTES DE OCA, Luis, "La estructura y Organización de los Órganos de Justicia Contenciosa Administrativa”, en FERNÁNDEZ RUIZ, Jorge y OTERO SALAS, Filiberto (coord.), Justicia Contenciosa Administrativa Congreso Internacional, México, Ed. UNAM, 2013

SERRA ROJAS, Andrés, Derecho Administrativo Segundo Curso, Ed. Vigésima sexta, México, Ed. Porrúa, 2010.

\section{LEGISLATIVAS}

Estado de Michoacán, Congreso Legislativo del Estado de Michoacán, "Código de Justicia Administrativa del Estado de Michoacán de Ocampo", Periódico Oficial del Estado de Michoacán, 27 de agosto de 2007, última reforma el día 14 de diciembre de 2012, (en línea) http://transparencia.congresomich.gob.mx/media/documentos/trabajo_ legislativo/CÓDIGO_DE_JUSTICIA_ADMINISTRATIVA_DEL_ESTADO_DE_ MICHOACÁN_DE.pdf.

Estado de Michoacán, Congreso Legislativo del Estado de Michoacán, “Constitución Política del Estado Libre y Soberano de Michoacán de Ocampo”, Periódico Oficial del Estado de Michoacán, publicada los días 7, domingo 10, jueves 14, domingo 17, jueves 21, domingo 24, jueves 28, de febrero; domingo 3, jueves 7 , domingo 10 y jueves 14 de marzo de 1918, última reforma el día 25 de junio de 2014, (en línea), http://transparencia.congresomich.gob.mx/media/documentos/trabajo_legislativo/CONSTITUCION_POLITICA_DEL_ESTADO_REF_25_DE_JUNIO_DE_2014.pdf.

México, H. Congreso de la Unión Cámara de Diputados, "Constitución política de los Estados Unidos Mexicanos”, Diario Oficial de la Federación 5 de febrero de 1917, última reforma 27 de mayo de 2015, (en línea) http://www.diputados.gob.mx/LeyesBiblio/ pdf/1_o7jul14.pdf.

Tratados e Instrumentos Internacionales Básicos en Derechos Humanos, Convención Americana Sobre Derechos Humanos (Pacto de San José), INmediación Asesores Publicitarios, Morelia, Michoacán, 2013.

Tratados e Instrumentos Internacionales Básicos en Derechos Humanos, Pacto Internacional de Derechos Civiles y Políticos, INmediación Asesores Publicitarios, Morelia, Michoacán, 2013.

CIBERNÉTICAS

FLORES NAVARRO, Sergio, Informe Anual de Actividades del Tribunal de Justicia Administrativa del Estado de Michoacán, presentando ante el H. Congreso de Michoacán 
de Ocampo, (en línea) http://transparencia.congresomich.gob.mx/media/documentos/gacetas/GACETA_142_C_19-02-2015.

Tribunal de Justicia Administrativa de Michoacán de Ocampo, Antecedentes Históricos del Tribunal de Justicia Administrativa del Estado de Michoacán de Ocampo, (en línea), http://www.tjamich.org/website/?page_id=7

OTROS

Escrito de Solicitud de información al Presidente de Tribunal de Justicia Administrativa del Estado de Michoacán de Ocampo, del día 02 de octubre de 2013, suscrito por el licenciado en Derecho Daniel Tovar Reyes.

HERRERA RODRÍGUEZ, Rubén, "El cumplimiento de las Sentencias Condenatorias en el Proceso Administrativo en el Estado de Michoacán y los Medios de Apremio para su Ejecución" (Que para obtener el grado de doctor en Derecho), Morelia, Michoacán, Instituto Internacional del Derecho y del Estado, 2013.

Oficio TJAM/SA/285/2013, con fecha 30 de octubre de 2013, mediante el cual el Tribunal da respuesta a la solicitud de información, el cual se encuentra suscrito por el licenciado Héctor Gómez Trujillo, Secretario Administrativo y Responsable de Acceso a la Información Pública del Tribunal de Justicia Administrativa del Estado de Michoacán de Ocampo. 
